\title{
Evaluation of pH of Drilling Fluid Produced from Local Clay and Additives
}

\author{
OTITIGBE, FE
}

Department of Chemical and Petroleum Engineering, Faculty of Engineering, Delta State University, Oleh Campus, Delta State, Nigeria Email:fotitigbe@yahoo.com;Tel: 08055626750,08177262500;09017725501

\begin{abstract}
Maintaining the $\mathrm{pH}$ of drilling fluid with suitable additives is one of the important operation for efficient drilling operations. However, commercial hydroxides are mostly used to control the $\mathrm{pH}$ of the drilling fluid. This paper evaluates locally sourced $\mathrm{pH}$ additives of burnt plantain heads (BPH), burnt ripe burnt ripe plantain peels (BRPP), and burnt banana plantain peels (BBPP) in comparison with conventional potassium hydroxide (KOH) and sodium hydroxide $(\mathrm{NaOH})$ as suitable agents to control $\mathrm{pH}$ of drilling fluid. The drilling fluid as prepared with bentonite and local clay in different concentrations of $\mathrm{KOH}, \mathrm{NaOH}, \mathrm{BPH}, \mathrm{BRPP}$ and BBRPP including Traona. The result of the study showed that $\mathrm{pH}$ of the drilling improved with respective use of conventional $\mathrm{KOH}, \mathrm{NaOH}, \mathrm{BPH}$, $\mathrm{BRPP}$ and BBRPP as additives. In addition, $\mathrm{KOH}$ showed the maximum percentage of degree (\%) of improvement on the drilling fluid with $38.46-45.45 \%$ compared with $27.2-40 \%$ for $\mathrm{NaOH}$. On the other hand, BRPP achieved 27.2$41.2 \%$, followed with $20-33 \%$ and $20-29.4 \%$ for BPH and BBPP respectively. Thus, the locally sourced additives could be used to enhance the $\mathrm{pH}$ and properties of drilling fluid.
\end{abstract}

\section{DOI: https://dx.doi.org/10.4314/jasem.v25i4.11}

Copyright: Copyright $(\odot 2021$ Otitigbe. This is an open access article distributed under the Creative Commons Attribution License (CCL), which permits unrestricted use, distribution, and reproduction in any medium, provided the original work is properly cited.

Keywords: Conventional pH additives, locally sourced pH Additives, Bentonite, Drilling Mud.

Drilling is one of the processes involved in upstream crude oil production. Drilling involves the use of drilling mud, which are complex mixtures of different interactive components. The properties of the drilling mud changes and majorly it is a function of pressure, temperature, time, rate of penetration and nature of formation of the drill and location of the well (Abdulsalam et al., 2020; Okorie, 2009). These interactions among the different component leads to varying degree of changes in properties such as viscosity, filtration, solid content, and importantly the $\mathrm{pH}$ of the drilling fluid during drilling operations. Hence, the properties of the drilling mud are controlled during drilling, in order to avoid challenges that could develop during drilling operations. Hence, it is very important to understand changes in drilling fluid characteristics. Apparently, drilling mud ease to transport the cuttings to earth surface, and consequently, cleaning the wellbore. Series of diagnostics tests are conducted on the drilling mud, which is mainly aimed to control the properties of the drilling mud. Pal, (2011) and Mahmood et al., (2016) reported that the presence of dissolved gases such as carbon dioxide, hydrogen sulfides in drilling mud leads to corrosion, which substantially impacts the reliability of down-hole equipment. Importantly, the $\mathrm{pH}$ of drilling mud is one of the key parameters to determine its performance. As such, it performs better within $\mathrm{pH}$ range of 8.0 to 10.5 for water base mud (Peretomode, 2018). Drilling mud lower than $\mathrm{pH} 7$ suggests it being acidic, which leads to pitting, corrosive to materials and equipment, and simultaneously result in environmental pollution (Okorie, 2009).Therefore, maintaining the $\mathrm{pH}$ of the drilling fluid within defined standard range is important during drilling operations. Maintaining the $\mathrm{pH}$ of drilling fluid at 8.0 to 10.5 has been reported by using conventional chemical such as soda ash $\left(\mathrm{Na}_{2} \mathrm{CO}_{3}\right)$ and the hydroxides of: sodium $(\mathrm{NaOH})$, potassium $(\mathrm{KOH})$, and calcium $\left(\mathrm{CaOH}_{2}\right)$. Although, a lot of success has been recorded with these aforementioned chemicals, it has led to drastic changes in the rheological properties of the drilling mud. Therefore, controlling the $\mathrm{pH}$ of drilling mud properties is still required. Use of the conventional chemicals mentioned inevitably leads to occurrence of contaminants such as chlorides, sulfides and the calcium carbonates. The contaminant result in mud thickness and or thinness, separation of mud components, consequently, leading to drastic changes in the drilling mud properties. At this point, treating the drilling mud or its modifications in regards to its $\mathrm{pH}$ by using $\mathrm{pH}$ additives becomes necessary. Review of the scientific literature showed that there is limited information on production of locally $\mathrm{pH}$ additives from solid waste products (Abo Taleb et al., 2020) such as burnt plantain peels and palm heads. Therefore, investigation on use of waste product to produce $\mathrm{pH}$ additives, in order to compliment conventional chemicals would be necessary. The use 
of locally sourced additive has been reported to be environment friendly, leads to no substantial negative effects on subsurface formation. Importantly, this approach would reduce cost of drilling and importantly it is in line with the Nigerian Local Content Laws in the Petroleum Industry (Abdulsalam et al., 2020). Omole et al., (2010) investigated the rheological and filtration properties of drill mud prepared with clay and reported that the clay may be as good as the conventional clay if it is properly treated. Peretomode, (2018) reported on the comparative analysis of using plantain peels powder and burnt palm head sponge powder with commercial $\mathrm{NaOH}$ as additives on drilling mud. The result showed that there was no substantial difference in rheological properties of drill mud following the use of $\mathrm{NaOH}$ and the locally sourced additives. Recently, Abdulsalami et al., (2020) investigated the effect of local $\mathrm{pH}$ additives sourced from plantain and banana peels on $\mathrm{pH}$ and viscosity of in drilling fluid systems, and concluded that the locally sourced were good $\mathrm{pH}$ enhancers for the formation of water-based drilling mud. These previous studies have shown the feasibility of using locally sourced materials as $\mathrm{pH}$ additives. However, it is not clear if the concentration of the $\mathrm{pH}$ additives had any substantial effect on drilling mud. Therefore, the main aim of this study is to evaluate the $\mathrm{pH}$ of drilling fluid prepared by using local clay Ameloko et al., (2020)., Akinade et al., (2015) and additives in varying concentrations.

\section{MATERIALS AND METHODS}

The local clay used for this research was obtained from Irhodo village in Ethiope West Local Government area of Delta State, Nigeria. The geographical directions are longitude 5 50'41' E (5.82811) and latitude $5^{\circ} 52^{\prime} 44^{\prime} \mathrm{N}(5.86216)$, and elevation of $23 \mathrm{~m}, 75.46 \mathrm{ft}$, 905.51 above sea level. The palm head and plantain peel were collected from Oleh (Lat. 5'27'32.17, 5,458936 and Long. $\left.6^{\circ} 12^{\prime} 11.13,6.203092\right)$ town, in Isoko south local government area of Delta State. Also, the Trona (AK-P) popularly called Akanwu was purchase at Oleh local market.

Sourcing and Processing of Local Clay sample: The clay was obtained from a depth of 3 feet above the sea level and the large visible particle were removed and stored in a black cellophane bag to prevent it from being contaminated. For purification, the raw local clay sample was diluted with de-ionized water (Ahmend et al. 2012) and allowed to swell for 72 hours, while being stirred at every 12 hours. This is in order to release inherent organic materials. After 72hours, the clay sample was sieved with 200-mesh Tyler's sieve and allowed to hydrate before being transferred into jeans bag for de-watering. Then, the dewatered clay sample was spread over a plane surface and allowed to sundry for 7days in accordance to James et al., (2008). Thereafter, the clay was grinded with mortar and pestle to fine particles and then sieved with a 200 mesh.

Preparation of local $\mathrm{pH}$ Additives: The $\mathrm{pH}$ materials (BPH, BRPP, and BBPP) were dried under sun, burnt and grinded into powder ash before sieving with 200 mesh size (74 microns) to further remove impurities in accordance to Okorie, (2009). The Trona (AK-P) was crushed to fine powder with a native mortar and pestle. Then sieved with a 200 mesh size of 74 microns to obtain a fine talc size powder, package and stored in cupboard prior to further use.

Experiment Procedure: An equivalent one barrel of laboratory drill mud (spud mud) sample was prepared by diluting $24.5 \mathrm{~g}$ of clay for both local $(\mathrm{pH} 6.0)$ and conventional bentonite $(\mathrm{pH} 9.5)$ and $0.5 \mathrm{ml}$ of sodium hydroxide $(\mathrm{NaOH})$ as additive with $350 \mathrm{ml}$ of distill water ( $\mathrm{pH} 7.0$ ). The addition of sodium hydroxide enhances the bentonite quality (Karaguiliizel $\mathrm{C}$ et al., 2010). The resultant mud sample was stirred in a mud mixer for $20 \mathrm{~min}$. Then the mixture was allowed to stand for 24 hours at room temperature, after which it was stored in a cupboard before further analysis. Six samples of additives were prepared; two from conventional bentonite $(\mathrm{KOH}$ and $\mathrm{NaOH})$ and four from local additives (BPH, BRPP, Trona and BBPP). Each sample was prepared into ten (10) different concentrations of $1 \mathrm{ml}, 2 \mathrm{ml}, 3 \mathrm{ml}, 4 \mathrm{ml}, 5 \mathrm{ml}, 6 \mathrm{ml}, 7 \mathrm{ml}$, $8 \mathrm{ml}, 9 \mathrm{ml}$ and $10 \mathrm{ml}$.

pH Test: For analysis, the each sample was stirred for 3 min followed with $\mathrm{pH}$ test using $\mathrm{pH}$ paper (the 1 inch universal) strip indicator and $\mathrm{pH}$ meter (Model Jenway 3520) at a temperature of $26^{\circ} \mathrm{C}$.

Test for additives level of impartation on drill mud $\mathrm{pH}$ : The influence of both locally sourced $\mathrm{pH}$ additives and conventional additives on the drilling mud samples formulated with local clay and foreign bentonite was tested. Firstly, with distilled water and then, drill mud samples at a varying concentrations of $\mathrm{pH}$ additives solutions of $1 \mathrm{mls}, 2 \mathrm{mls}, 3 \mathrm{ml}, 4 \mathrm{ml}, 5 \mathrm{ml}, 6 \mathrm{ml}, 7 \mathrm{ml}, 8 \mathrm{ml}$, $9 \mathrm{ml}$, and $10 \mathrm{ml}$ using $\mathrm{pH}$ paper strip and $\mathrm{pH}$ meter as mentioned previously.

\section{RESULTS AND DISCUSSION}

The data obtained from the different additives at varying concentrations in distilled water is presented in Figure 1. As shown in Figure 1, locally sourced and conventional $\mathrm{P}^{\mathrm{H}}$ additives showed impressive results of neutral solution (p9iwith a pH7.0) at all concentrations. However, the $\mathrm{pH}$ values was found to 
remain constant with further increase in concentration of the additives but still remained within the range of 7.5 to 11.0 . This finding suggests that the additives contain a strong base element. Furthermore, the burnt ripe plantain peel (BRPP) additive at a concentration of $4 \mathrm{ml}$ was found to attain a $\mathrm{pH}$ value of 10.0. This also indicates consisting of much stronger base element, and also being very reactive when compared to other additives such as BPH, BBPP. Also shown in Figure 1 , the $\mathrm{pH}$ values of all the additives remain unchanged at concentrations of 8.0 to $10.0 \mathrm{ml}$. This phenomenon could be due to the strong cohesive bond of the respective additive, which might have resisted further reaction in electron sharing. The conventional additives of $\mathrm{KOH}$ and $\mathrm{NaOH}$ showed good results of maintaining an alkaline medium, especially, $\mathrm{KOH}$ that had a high $\mathrm{pH}$ from the beginning till when its $\mathrm{pH}$ value remained constant at 11.0. On the other hand, the local additives (BPH, BRPP, BBPP and Trona) also showed promising result of an alkaline medium, which was found to be within the pH scale (API, 2010). In comparison, both locally sourced additives have similar $\mathrm{pH}$ when compared with that of conventional additives in the distill water and as such the local additives could use to complement its counterpart. Although, there was variations in the mud $\mathrm{pH}$ value obtained from different additives, all additives were found to have $\mathrm{pH}$ value that is within standard range of 8.5 to 10.5 . KOH was found to be better when compared to $\mathrm{NaOH}$, as it attained $\mathrm{pH}$ value at lower concentrations. For the locally sourced additives, BRPP was found to be better when compared to BPH and BBPP. BRPP showed closer similarities with that of the conventional $\mathrm{KOH}$ additives.

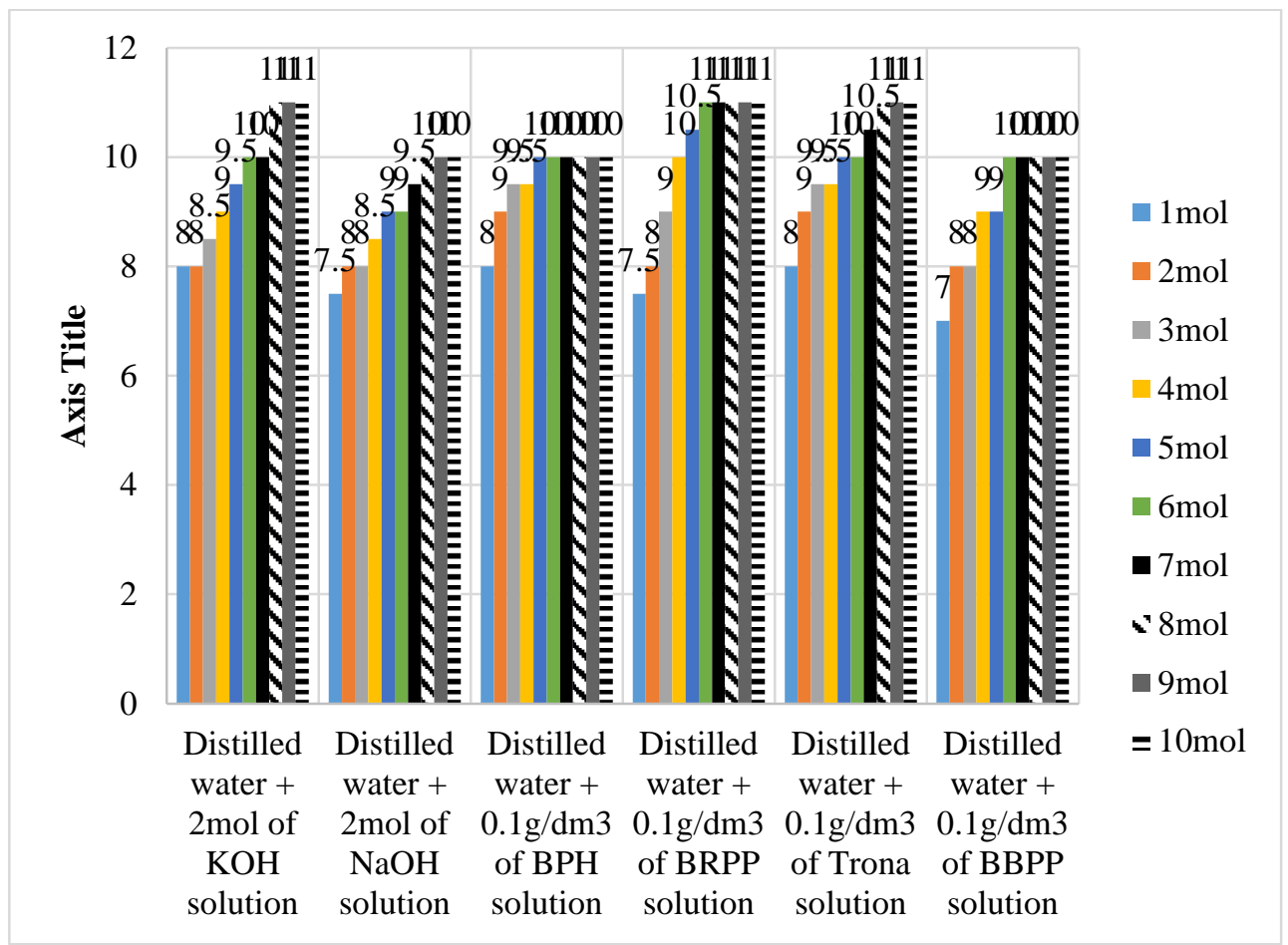

Fig1: $\mathrm{pH}$ of different additives at varying concentrations in distilled water of $\mathrm{pH}$ of 7.0

The data obtained for the $\mathrm{pH}$ of the difference additives in drill mud formulated with local clay (Irhodo) is shown in Figure 2. Generally, in the $\mathrm{pH}$ scale of reference (API, 2010), the numerical value of 7.0 , indicate a neutral solution, while less than 7.0 is acidic and those greater than 7.0 are alkaline. Based on the data presented in Figure 2, the conventional additives in the drill mud prepared with the local clay obtained from Irhodo village at initial concentration showed had a $\mathrm{pH}$ value of 7.0 , which means neutral and not acidic. Further increase in concentration, the $\mathrm{pH}$ values for both conventional additives $(\mathrm{KOH}$ and $\mathrm{NaOH}$ ) increased from 7.0 to 11.0. However, the mud
$\mathrm{pH}$ remained constant with increase in concentration. This suggests that both additives started exhibiting alkalinity with increase in concentrations. The $\mathrm{KOH}$ display an impressive result at all level of the test from $2 \mathrm{ml}$ to $10 \mathrm{ml}$ when compared with $\mathrm{NaOH}$. Hence, $\mathrm{KOH}$ could be a more suitable $\mathrm{pH}$ additive to prepare drill mud when compared to $\mathrm{NaOH}$ in drilling operations of oil and gas wells. On the other hand, the $\mathrm{pH}$ additives sourced from local waste materials; $\mathrm{BPH}$, BRPP, BBPP except Trona in drill mud, exhibited characteristics of acidic, neural and alkaline. This was clearly seen in BPH having a $\mathrm{pH}$ value of 7.0 (neutral), while BRPP and BBPP showed 6.0 and 6.5, 
respectively, while Trona have a test value of 7.5 and is an indicative of alkaline medium. The values 6.0 and 6.5 indicate an acidic value, which could be due to the swampy environment where the clay was obtained that is largely known to be associated with acidic formation. The BPH at $1 \mathrm{ml}$, on beneficiation, showed high alkalinity that subdues the acidic properties in the drill mud. In addition, Trona at $1 \mathrm{ml}$ showed a $\mathrm{pH}$ value of 7.5 , which is alkaline. This may be mostly due to high concentrations of alkaline in Trona that could have reduced the influence of acid in the drill mud. Also, this may be the major reason why Trona performed better than the rest of local additives (BPH, BRPP and BBPP). Although, the conventional $\mathrm{pH}$ additives were good, the locally sourced additives could be used to complement the conventional additives, if consciously beneficiated or treated.

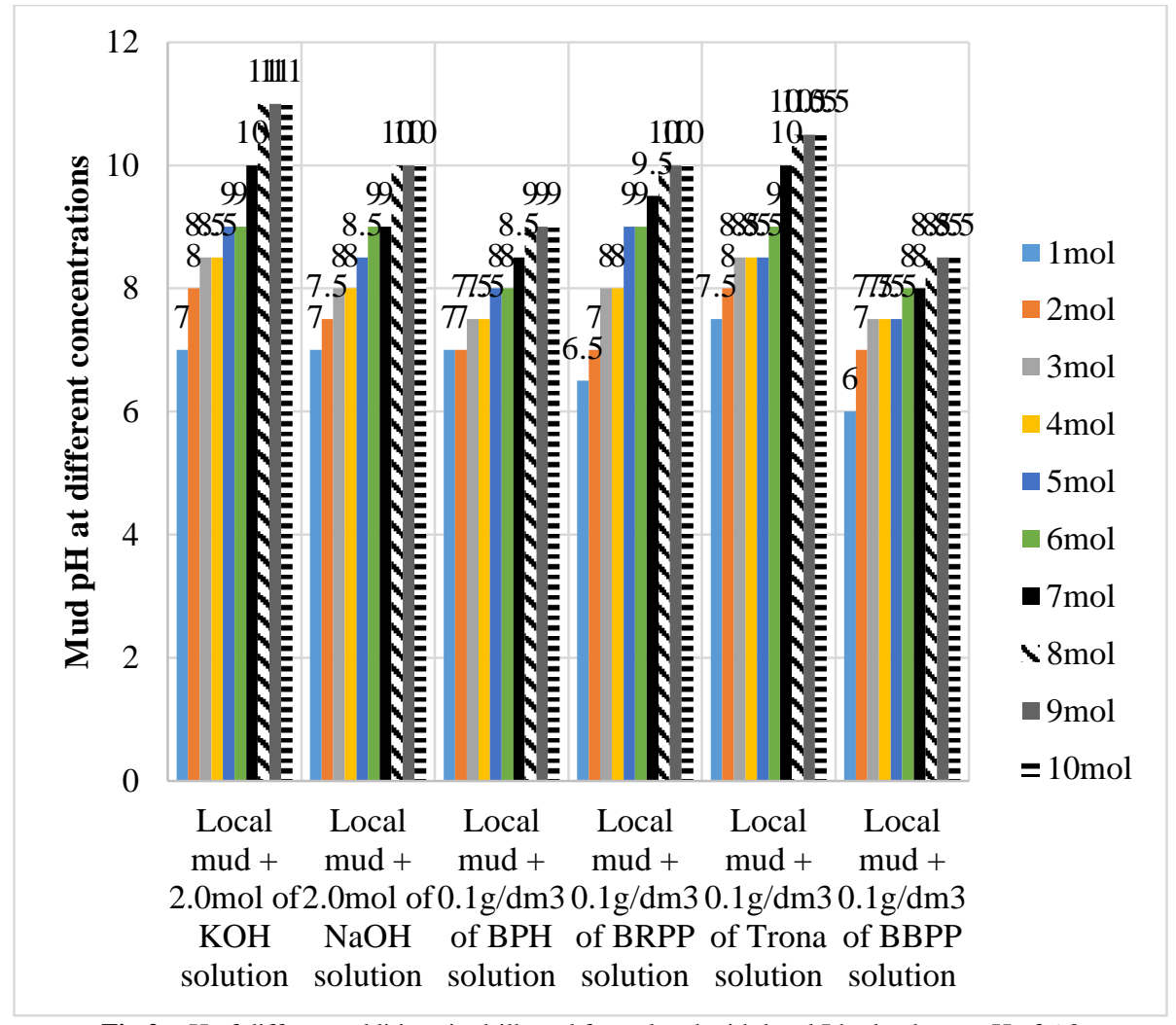

Fig 2: $\mathrm{pH}$ of different additives in drill mud formulated with local Irhodo clay at $\mathrm{pH}$ of 6.0

The results of the $\mathrm{pH}$ values of the different additives prepared with conventional clay ( $\mathrm{pH}$ value of 8.0 ) are presented in Figure 3. As illustrated in Figure 3, the conventional $\mathrm{pH}$ additives of $\mathrm{KOH}$ and $\mathrm{NaOH}$ at the beginning of beneficiation at $1 \mathrm{ml}$, exhibited high value of alkaline, especially, $\mathrm{KOH}$ having a value of 9.5. This may be due to the $\mathrm{KOH}$ being more resistive to dilution and thereby maintaining its concentration much longer than $\mathrm{NaOH}$. Hence, this showed that $\mathrm{KOH}$ may perform very well than $\mathrm{NaOH}$ in the drill mud as mentioned previously. Furthermore, the locally sourced $\mathrm{pH}$ additives (BPH, BRPP and BBPP) except Trona, exhibited an alkaline medium on beneficiation with $1 \mathrm{ml}$ of solution. This was expected as Trona that had the maximum $\mathrm{pH}$ value of 9.0 while $\mathrm{BPH}, \mathrm{BRPP}$ and BBPP have their respective $\mathrm{pH}$ of 8.5, 8.0 and 8.0. The swelling value of 8.5 of Burnt Palm
Head over the BRPP and BBPP may be due to presence of high base content. In summary, $\mathrm{KOH}$ showed the maximum percentage of degree $(\%)$ of improvement on the drilling fluid with $38.46-45.45 \%$ compared with $27.2-40 \%$ for $\mathrm{NaOH}$. On the other hand, BRPP achieved 27.2-41.2\%, and this was followed with $20-33 \%$ and $20-29.4 \%$ for BPH and $\mathrm{BBPP}$ respectively. The aforementioned data suggest that the locally sourced additive e.g. BRPP perform relatively when compared with conventional $\mathrm{KO}$ and $\mathrm{NaOH}$. This finding reaffirms that BRPP and BBPP may be used as a $\mathrm{pH}$ enhancing additives for drilling fluids. Although, the main focus of this study was evaluating $\mathrm{pH}$ of locally sourced additive, previous studies has reported their effects on other parameters such as viscosity of the drilling fluid. For example, Abdulsalami et al., (2020) reported that banana peel 
powder led to an increase of the drilling from $7.00 \mathrm{cP}$ to: $11.50 \mathrm{cP}$, and to $19.00 \mathrm{cP}$ for plantain peel additives. Also an increased in $\mathrm{pH}$ for plantain powder (9 to 11.75) and banana powder (up to 11.42) additives was reported. Peretomode (2018) reported increased in $\mathrm{pH}$ of drilling mud from 9 to 11-135 for commercial $\mathrm{NaOH}$, then from $\mathrm{pH} 9$ to $10-12$ for plantain peels powder, while the burnt palm head sponge powder achieved increased in $\mathrm{pH}$ from 9 to $10.5-13$. In addition, plastic viscosity and apparent viscosity of 4-
$6 \mathrm{cP}$ and $6.5-12.5 \mathrm{cP}$ for $\mathrm{NaOH}, 5 \mathrm{cP}$ and $6.5-11 \mathrm{cP}$ for locally sourced additives was reported. In the present study, the $\mathrm{pH}$ was found to be within range of previous report, which could also suggest the trend in viscosity may be similar. This study has shown that solid waste agricultural products could be used to produce local additives to complement conventional ones. Such activities would reduce pollution, reduce cost of production (Samson and Saheed, 2021) and improve the economy.

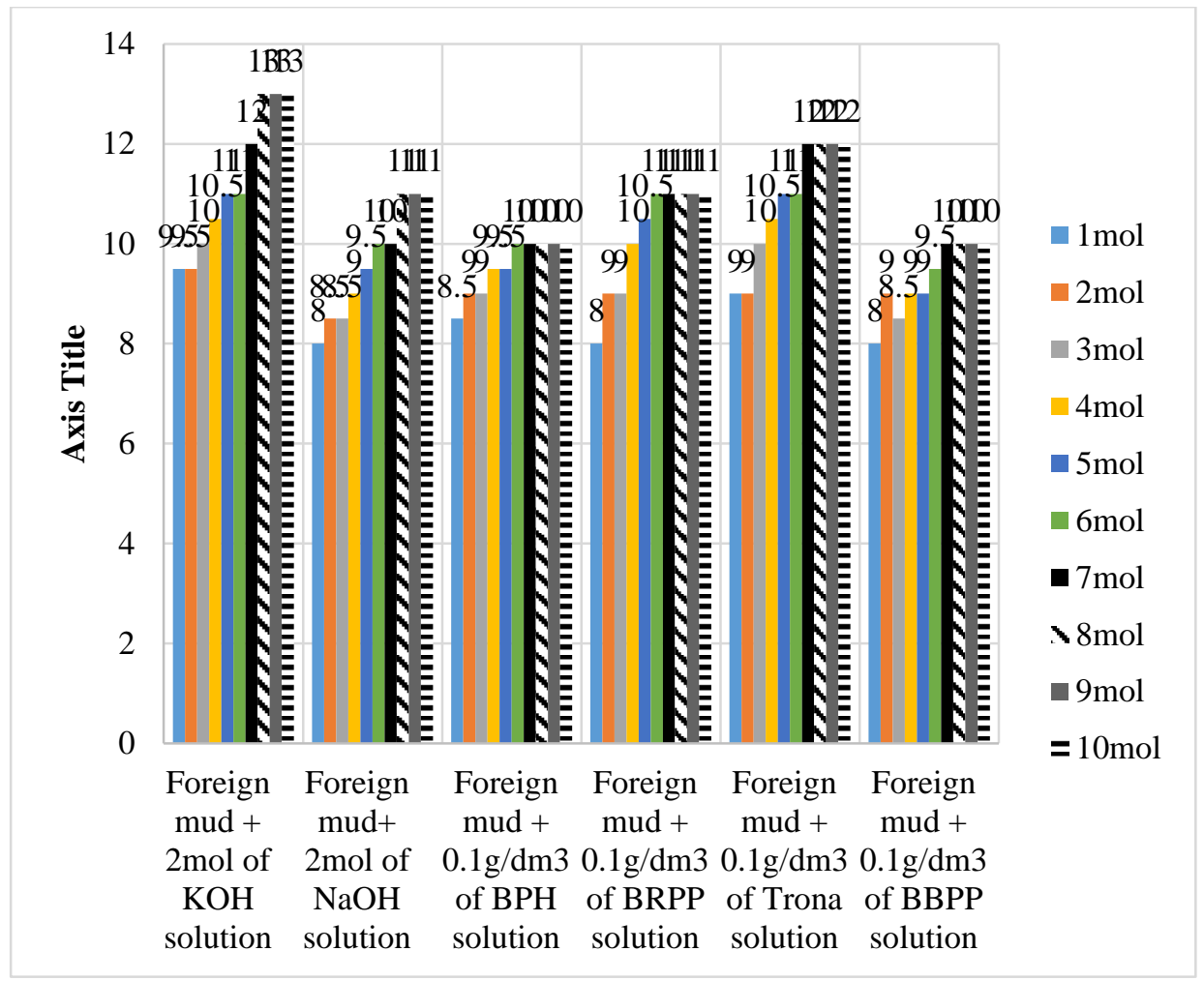

Fig3: $\mathrm{pH}$ of different additives in mud formulated with conventional clay of $\mathrm{pH}$ value of at 8.0

Conclusion: This study evaluated the $\mathrm{pH}$ additives obtained from local and conventional materials. The result showed that waste materials are useful to produce additives, of similar properties when compared with those from conventional materials. $\mathrm{KOH}$ could be more suitable $\mathrm{pH}$ additives to prepare drill mud than $\mathrm{NaOH}$ in drilling operations of oil and gas wells. The additives BPH, BRPP, BBPP except Trona from local waste materials characterized with acidic, neural and alkaline. BPH was found more suitable when compared to BRPP and BBPP.

\section{REFERENCES}

Abdulsalam et al., (2020). Analysis of bio-enhancers for $\mathrm{pH}$ and viscosity control in drilling fluid systems. Int. J. of Res. and Innov. Appl. Sci. 5: 242-247.
Abo Taleb Al-Hameeedi et al., (2020). Utilizing a new eco-friendly drilling mud additives Generated from waste to minimize the use of conventional Chemical additives. J. Pet. Expl. Prod. Tech. $10: 3467-3481$

Akinade et al., (2015). Experimental investigation of the use of local clay (Abbi, DeltaState, Nigeria as a substitute for foreign imported bentonite clay in the formulation of aqua base drilling fluid. Int. J. Sci. Eng Res.6 (6), 1138-1143.

Ameloko et al., (2020). Assessment of clay materials for suitability in drilling mud formulation from part of Ondo State, South-West, Nigeria. J. of Pet. and Prod. Tech. 10: 2815-2828. 
American Petroleum Institute, (2010). API SPEC 13A: Specification for Drilling Fluid Materials. (18 ${ }^{\text {th }}$ Edition).

Karagiliizel, K (2010). Activation of (Na, Ca)bentonites with soda and $\mathrm{MgO}$ and the utilization as drilling mud. Appl. clay Sci. 48(3), 398-404

Mahmood M (2016). Safe practices in drilling and completion of sour gas wells. J. of Pet. and Envtal. Biotech. 7(4), 1- 8.

Omole et al., (2013). Investigating into the Rheology and Filtration properties of drilling mud formulated with local clays from northern Nigeria. J. Pet. and Gas Eng 4(1), 1-13
Peretomode, JP (2018). Plantain Peels Powder, Burnt Palm Head Powder and commercial Sodium Hydroxide as additives for water Base Drilling mud. J App Sci. Environ. Manage. 22(7). 10091012

Samson, SS; Senbore, AO (2021). Geophysical and Geochemical Assessment of Afuze Bentonitic Clay: Implication for mud Drilling Additive in Drilling Industry. IOP Conference Series: Earth. Environ. Sci. 690. 012034. 